\title{
O LUGAR DA PEDAGOGIA NO MUNDO CIENTÍFICO E O PAPEL DAS DISCIPLINAS DE BASE*
}

\author{
Bruno Gonçalves Borges, \\ da Universidade Federal de Goiás (UFG); \\ Décio Gatti Júnior, \\ da Universidade Federal de Uberlândia (UFU).
}

\begin{abstract}
Resumo: O artigo a seguir trata da abordagem histórica da constituição ou pretensão constitutiva da pedagogia enquanto ciência da educação. Tem como objetivo analisar, por meio da bibliografia especializada, sobretudo de História da Educação/Pedagogia, as ações afirmativas do modelo clássico de ciência que se impôs à pedagogia já no século XX. O método utilizado para essa investigação esteve centrado na análise comparativa das obras e na identificação das matrizes do pensamento pedagógico. Percebe-se que, com tal empreendimento, a pedagogia obteve resultados diferentes do esperado, derivando, muitas vezes, no esvaziamento da própria reflexão pedagógica.
\end{abstract}

Palavras-chave: História da Educação. Pedagogia. Experiência. Experimento.

INTRODUÇÃO

"A história é a ciência dos homens, dos homens no seu tempo" (Marc Bloch).

"A pedagogia é a ciência do homem em formação" (Pedro Anísio).

A epígrafe que inaugura essa etapa do texto cabe à célebre frase de Marc Bloch, historiador francês e a um empenhado pedagogo nordestino, brasileiro, dos anos 1930, e inspira o aspecto concorrencial,

\footnotetext{
* Artigo recebido em 26/10/2012 e aprovado em 18/01/2013.
} 
próprio dos séculos XVIII e XIX, em que o estabelecimento das ciências humanas enfrentava as resistências da comunidade científica reconhecida. ${ }^{1}$ Concomitantemente, essas ciências lidavam entre si pela definição de campo, método e reconhecimento, ao passo que, sendo o homem ${ }^{2}$ o objeto comum para todas, cabia a cada uma basear-se em um "eixo epistemológico"3 sobre o qual seria constituída,

[...] explicando seus fenômenos a partir de um lugar não filosófico e não ideológico, como se pudessem reivindicar, de modo peremptório, a categoria de "corte epistemológico" para expressar suas distâncias relativamente a toda filosofia e a todo sistema de representação ideológica. (JAPIASSU, 1978, p. 95)

Nesse movimento, a epígrafe do monsenhor Pedro Anísio (1934) ilustra o que, de forma especulativa, colabora para a pedagogia ser tomada como ciência: o reconhecimento de que ocorre uma intervenção no homem, em dado momento da vida em que precisa ser formado e inserido em um mundo já produzido de acordo com a história.

$O$ debate em torno da cientificidade dessa disciplina frequentou os diversos tratados publicados desde os anos finais do século XVIII. Franco (2008) destaca que são inúmeros os livros que se ocupam em defender o caráter científico da pedagogia e cita, ao menos, dez consagradas obras da área de autores como Compayré, Hubert, Luzuriaga e Monroe.

Nesse sentido, os esforços de cientificização se voltam para a produção de uma literatura direcionada a qual, primeiro, é destinada ao grupo de interesse imediato, formado por professores, pedagogos e estudantes que precisam tomar partido na defesa de sua ciência. Posteriormente, é dirigida ao público geral, por meio da vulgarização desse conhecimento e, sobretudo, aos pares acadêmicos das demais áreas em busca de reconhecimento e espaço. Dessa forma, a produção de livros, a realização de encontros e conferências, a difusão em meios de comunicação de massa e, de modo especial, o ensino convergem para a formação de um corpus científico da pedagogia que se pretende estabelecer.

Quanto ao ensino, os primeiros cursos de Pedagogia de que se tem notícia, muito embora não haja garantia de terem existido com esse nome, foram: o de Charles Démia ${ }^{4}$ (1637-1689) no seminário Saint-Charles, em Lyon (França), no ano de 1678; ${ }^{5}$ e o ministrado por Jean Baptiste de La Salle (1651-1719), oferecido à formação de novos mestres, em 1685, na forma de uma instrumentalização imediata para o exercício do magistério. Na época, conforme definiu La Salle, a formação do professor consiste em duas medidas: 
"(1) em tirar dos novos mestres o que têm e não devem ter; (2) em dar-lhes o que não têm e é muito necessário que tenham". ${ }^{6}$ Cursos como esses, de curta duração e de teor essencialmente prático, tiveram ocorrência em diversas partes da Europa no final do século XVII (MIALARET; DOTTRENS, 1974, p. 42), prolongando-se até que, pouco a pouco, a presença do Estado moderno estruturasse o modelo de formação por meio de instituições específicas, como o caso das Escolas Normais, o que deslocou a formação do professor do espaço confessional para o estatal.

No âmbito do ensino universitário, é criado na França, no ano de 1882, o primeiro curso de Pedagogia na Faculdade de Letras da Universidade de Bordeaux. No ano de 1883, Jules Ferry cria, na Universidade Sorbonne, seu curso de Pedagogia no qual se destacariam, ao longo do tempo, Henri Marion, Ferdinand Buisson e Émile Durkheim. A característica básica desses primeiros cursos é a complementação da formação dos mestres dada nas Escolas Normais Superiores e, mais tarde, assumiram a profissionalização de professores secundaristas e primários, técnicos educacionais e pesquisadores (BASTOS, 2006, p. 3; MIALARET; DOTTRENS, 1974, p. 46).

Compayré (1843-1913) chama atenção para a ocorrência de cursos de pedagogia na Universidade Imperial de Tóquio, no Japão, e nas universidades norte-americanas, onde já se tinha notícia da existência de doutorado na área. A pedagogia frequentava, à época, até mesmo universidades consagradas como Harvard, Clark e Genebra; e, na Alemanha, o curso estava presente em pelo menos oito universidades, entre elas a de Berlim e de Estrasburgo ${ }^{7}$ (MIALARET; DOTTRENS, 1974, p. 45).

A presença do curso na academia francesa é, então, fundamental para o desenvolvimento da pedagogia universitária, vinculada, no país, a duas vertentes centrais. De um lado, a pedagogia "sociológica", empreendida por Marion, Buisson e Durkheim; de outro, a pedagogia "histórica”, de Gabriel Compayré.

O processo de cientificização é complexo e demasiado longo. Poderia uma análise, nesse sentido, partir em busca das publicações periódicas em jornais e revistas pedagógicas que se disseminam pela Europa e Estados Unidos e, depois, por todo mundo. Ou, também, dedicar-se ao aparecimento e organização das sociedades científicas e associações profissionais que começam a surgir nos séculos XIX e XX, como, por exemplo, o Instituto Pedagógico Internacional (1911) na França e o Instituto Nacional de Pedagogia (1937) no Brasil; este último um embrião do atual INEP - Instituto Nacional de Estudos e Pesquisas Educacionais Anísio Teixieira - o qual teria uma inspiração anterior, ainda à época do Império, o Pedagogium ${ }^{8}$ de 1890. Poderia, ainda, 
ocupar-se dos seminários e congressos em nível nacional (França, Espanha, Estados Unidos e outros) e internacional, como a Liga Internacional para a Educação Nova (1932), o Bureau International d'Éducation (1954) e as edições do Congresso Internacional do Ensino Universitário da Pedagogia (o segundo realizado na cidade de Florença em 1957).

Diante da proposta de situar as discussões em torno da pedagogia, como ciência da educação, foi feita a opção por se buscar, na produção bibliográfica especializada, a definição e o lugar que lhe são atribuídas em algumas obras de grande circulação no século XX. ${ }^{9}$

Dentre a ampla produção de livros dedicados à formação de pedagogos e professores, foram selecionadas as obras a seguir: em uma perspectiva filosófica, encontra-se o Tratado das ciências pedagógicas, ${ }^{10}$ organizado por Maurice Debesse e Gaston Mialaret e publicado no Brasil em 1974; na perspectiva psicológica, tem-se a Pedagogia científica de A. M. Aguayo, com publicação brasileira de 1936; por sua vez, na perspectiva sociológica francesa, há a História da Pedagogia de René Hubert, editado em 1976; e, por fim, a referência ao historicismo e vitalismo alemão, presentes na obra História da Educação e da Pedagogia, de Lorenzo Luzuriaga (1969), com forte influência do pensamento diltheano.

A seleção ${ }^{11}$ dessas obras baseia-se no fato de elas se referirem claramente à pedagogia como ciência; de serem títulos (originais e, posteriormente, traduções) que tiveram expressiva circulação no país; de serem direcionadas a um mercado em franco desenvolvimento, formado por estudantes das Escolas Normais, dos cursos de Pedagogia e licenciaturas. Além disso, outro motivo acabou por aparecer: as obras compõem a coleção Atualidades pedagógicas da Companhia Editora Nacional, revelando que a difusão por meio do livro - direcionado à formação dos pedagogos e professores - foi fundamental para a constituição de um "campo" e mesmo de um mercado editorial específico.

Assim como a obra Atualidades pedagógicas, as coleções editoriais dedicadas a professores ou futuros professores

podem ser analisadas como um tipo especial de impresso que carrega em sua materialidade dupla estratégia de intervenção cultural: a intervenção no campo da pedagogia, por meio da seleção e adaptação do conjunto de textos e autores que deve compor o programa específico de formação do professor-leitor, indicando os usos específicos para o conjunto das leituras selecionadas na coleção; [e] a intervenção editorial que, por meio da reorganização dos textos, para a ampliação do mercado, faz circular a representação do professor-leitor, objetivada pelo editor, e das práticas de leituras específicas e adequadas a ele. (TOLEDO, 2007, p. 1-2) 
Segundo a autora, esse tipo de publicação acaba por estabelecer uma cultura pedagógica própria, que autoriza o editor (por meio de sua mediação) e a empresa que assina a obra a atuarem para além da venda de livros, pois - ao lançarem no mercado obras de didática, de história da educação, psicologia da aprendizagem etc. - propiciam uma visão pontual de cada área, mas também acabam por fornecer uma visão geral do que é a Pedagogia, chegando mesmo a inspirar e divulgar um modelo de leitura, de literatura, de formação e de atuação profissional.

Publicada entre os anos de 1931 e 1981, Atualidades pedagógicas foi uma importante coleção com 134 volumes da Companhia Editora Nacional, ${ }^{12}$ empresa estabelecida na cidade de São Paulo em 1925, tendo entre seus fundadores Monteiro Lobato. A coleção - criada e dirigida até 1943 por Fernando de Azevedo, intelectual da educação e figura pública recorrente na política educacional - constituiu mais um instrumento de Azevedo na divulgação e na propagação da Escola Nova no país e estabeleceu um referencial de obras com alcance nacional.

Nesse contexto, o Tratado das ciências pedagógicas ${ }^{13}$ é o volume 113 da referida coleção e procura organizar, segundo a perspectiva filosófica, o conjunto de disciplinas e ciências que constituem a Pedagogia. A própria expressão "ciências pedagógicas" remete à intenção científica que se pretendeu investir na questão, sendo que, nesse empreendimento, "a filosofia está apta a dar, à educação, o caráter de totalidade que lhe faltaria se a educação dependesse somente das ciências humanas" (LÉVÊQUE; BEST, 1974 , p. 84).

Dottrens e Mialaret chegam a indicar - no Capítulo I do Tratado, intitulado O desenvolvimento das ciências pedagógicas e seu estado atual - uma proposta, mesmo que não claramente anunciada, de formação profissional a partir de uma base filosófica, quando defendem que a sociedade não está "mais no tempo em que os conhecimentos do pedagogo só podiam ser rudimentares" e que, nos tempos atuais, "a formação de um especialista em educação exige numerosos anos e competências muito variadas" (MIALARET; DOTTRENS, 1974, p. 32).

Nesse sentido, definem quais disciplinas principais constituem as denominadas ciências da educação, classificando-as em: reflexivas, documentais, fundamentais, aplicadas e pedagógicas. ${ }^{14}$ Segundo os autores, em primeiro lugar aparece a Filosofia, única a ser classificada como disciplina reflexiva. A Filosofia da educação, ${ }^{15}$ em especial, seria capaz de "pôr ordem, coerência, no diverso dos resultados alcançados por essas diferentes ciências particulares, forçosamente 'regionais' e parcelares" (LÉVÊQUE; BEST, 1974, p. 81). 
Dessa forma, constituída a espinha dorsal da pedagogia, a Filosofia, caberia às demais ciências atuarem de forma pontual sobre os aspectos da educação: a criação da escola, as formas de ensinar, os mecanismos de aprendizagem, entre outros, deixando revelar o papel de auxiliares. No conjunto das disciplinas documentais, estariam a História da educação e a Educação comparada, limitadas à função repositória de documentação sobre a educação, sistemas educacionais e métodos de ensino. Quanto à História da educação, essa função não difere do que ocorria de forma geral e do que se esperava da disciplina, ou seja, cabia a ela, organizar cronologicamente os documentos que tratavam da educação.

Os autores prosseguem anunciando as disciplinas fundamentais: a Biologia, a Psicologia e a Sociologia. É possível identificar, nessa classificação, a existência de um conflito, pois, no processo de cientificização da educação, as discussões foram amplamente amparadas pelas ciências denominadas por Dottrens e Mialaret (1974) como fundamentais. Fica explícita a contradição, quando defendem o protagonismo da Filosofia, ao mesmo tempo em que não podem desconsiderar, na Pedagogia, a forte presença da Biologia, da Psicologia e da Sociologia, dando a elas o caráter de fundamentos, pois, sabem os autores, que essas disciplinas ganham cada vez mais espaço em detrimento das abordagens filosóficas, especialmente, no decorrer do século XX.

Assim, a importância das disciplinas fundamentais pode ter sido diluída na classificação dos autores, uma vez que, essas ciências aparecem novamente em outro conjunto - as disciplinas aplicadas, as quais, "utilizando os métodos e as técnicas das ciências precedentes [as fundamentais], analisam de seu ponto de vista as situações educacionais" (MIALARET; DOTTRENS, 1974, p. 32). Nesse conjunto estão a Biopedagogia, a Psicopedagogia e a Sociopedagogia. Os prefixos empregados ao termo pedagogia são por si reveladores dessa fragmentação por parte dos autores, baseados em um entendimento que aposta na divergência entre teoria (fundamento) e prática (aplicação) das ciências, ou ainda, em um posicionamento convicto de que caberia mesmo à Filosofia "produzir, teorias da educação que permitissem organizar os fenômenos estudados pelas ciências humanas e, assim, facilitassem a passagem da ciência para a prática" (LÉVÊQUE; BEST, 1974, p. 82). Por fim, estariam as disciplinas "pedagógicas", responsáveis pelos estudos particulares da educação: métodos, conteúdos e formas de ensinar. Essas disciplinas são marcadas por duas vertentes, conforme exemplificou, no ano de 1924, o Dr. Th. Simon (Cf. MIALARET; DOTTRENS, 1974, p. 32-33): enquanto uma vertente centra-se nos problemas próprios da educação e do processo de desenvolvimento dos educandos, a outra se manifesta diante 
das preocupações científicas clássicas, atribulada em medir, enumerar e determinar condicionantes. A primeira vertente foi denominada de pedagogia experiencial e a segunda, pedagogia experimental.

A experienciação se faz presente na pedagogia desde o século XVIII. Essa prática estaria vinculada à ação dos conhecidos pensadores educacionais da época que, paralelo à reflexão filosófica que produziam, criaram escolas para transpor, à vida prática, os métodos e, principalmente, as concepções de educação propostos. Não se trata, no entanto, de testes de funcionalidade, nem mesmo de levar à exaustão a eficiência e eficácia das propostas, mas, acima de tudo, de propiciar experiências.

Por toda Europa ficaram conhecidas as escolas de Comenius e Jean Baptiste de La Salle, por exemplo. Há notícia, segundo Miliaret e Dottrens (1974), de que Pestalozzi, discípulo de Rousseau, tentou aplicar em sua escola as teorias extraídas do Emílio, mas, sem grande sucesso e, que, quando Herbart assumiu a cadeira de pedagogia, sucedendo Kant, na Universidade de Könisberg, quis ter uma escola para que seus alunos tivessem contato com os métodos no espaço que lhe é próprio.

Coube a Herbart, segundo a historiografia educacional, conferir a qualidade de ciência à Pedagogia. A aproximação do pensador alemão para com essa disciplina ocorreu nos anos de 1796 e 1799 e deve-se, em parte, ao contato com Pestalozzi na Suíça, sendo a ele creditada a inspiração para o desenvolvimento dos conceitos essenciais da pedagogia herbartiana que são a experiência e a circunstância externa.

Herbart nasceu em maio de 1776 em Oldenburg, na Alemanha. Estudou Direito, porém o contato com o movimento filosófico, especialmente como professores renomados como Reinhold e Fichte, bem como a aproximação com o pensamento kantiano distanciaram-no da advocacia. Em 1801, escreve seu primeiro ensaio, intitulado Ideias para um plano pedagógico de estudos para escolas secundárias. No ano seguinte, aprofunda-se no debate educacional e redige publicações sobre o método e a experiência de Pestalozzi. No mesmo ano, ingressa como professor de Pedagogia em Göttingen e, em 1806, apresenta sua principal obra da área - Pedagogia geral deduzida da finalidade da educação - que, como tudo indica, não teve grande destaque, na época, frente a outras obras de filosofia do pensador. Posteriormente, ensinou Pedagogia em Könisberg até 1833. Autor de diversos livros de filosofia e pedagogia morreu em abril do ano de 1941, aos 66 anos.

"Muito kantianamente, Herbart quis estabelecer, sobre o alicerce sólido da razão, a ciência da pedagogia, determinando as suas condições constitutivas", diferenciando-se, no entanto, quando se coloca em uma 
posição claramente realista frente aos problemas educacionais. Além disso, se para Kant a ciência pela qual se alcança a natureza do homem é a antropologia, para Herbart, caberia à psicologia tal função (PATRÍCIO, 1971, p. 6). Dessa forma, as bases da pedagogia herbartiana têm na psicologia e na ética o seu alicerce, sendo que

A psicologia dá-nos o homem no seu ser; a ética dá-no-lo no seu dever-ser. Assente na psicologia - que lhe dá o que é - e com os olhos colocados na ética - que lhe dá o ideal do homem -, à pedagogia cumpre realizar o itinerário da educação, ou seja, do aperfeiçoamento moral do homem. (PATRÍCIO, 1971, p. 6)

Nessa acepção, percebe-se que o lugar da psicologia não sobrepõe aquele ocupado pela filosofia. Essa é uma característica corrente na pedagogia de Herbart, pois, o interesse maior da educação está na formação do homem e não dotá-lo, puramente, de competências e habilidades para a posteridade. Cabia à psicologia, a interpretação do Ser como natureza, ou seja, oferecer um conhecimento sobre o homem que será instruído e propiciar recursos a serviço de uma instrumentalização e uma organização a cargo da pedagogia para o fim de desenvolver a moral.

No entanto, a psicologia passa a ter, cada vez mais, um alcance maior sobre a pedagogia e, de disciplina dedicada à compreensão da educação e do indivíduo, passa a investir na construção de modelos e métodos para a aplicação pedagógica. A finalidade atribuída por Herbart de se conhecer a natureza humana por meio dessa disciplina cede espaço para uma ciência "protagonista" que fundamentará toda reflexão e prática pedagógica, os modelos explicativos, os métodos, a literatura, a formação de professores e o fazer ciência. Eleva-se, dessa forma, à disciplina central das ciências da educação.

A pedagogia experiencial lança, assim, as bases da pedagogia científico-experimental e tem em Herbart seu principal representante que, para muitos, reduziu a educação à instrução, configurando o campo dessa "ciência" no processo de ensino e aprendizado formal. Aliás, essa pedagogia, para muitos, embora fundamentada, carecia de dispositivos de controle que the confeririam valor e eficácia. Sob essas exigências, a primeira é historicamente superada pela segunda.

A transformação que se opera na pedagogia, principalmente do final do século XIX em diante, é, basicamente, a transição da experiência para o experimento. Na construção desse novo paradigma está o aprofundamento nas questões psicológicas (que antes ocupavam uma preocupação secundária frente ao objetivo maior de ordem filosófica), a entrada maciça da medicina 
e da biologia e, sobretudo, todo esforço em elevar a pedagogia ao patamar de ciência, por meio da aproximação, mais que possível, dos modelos consagrados das ciências naturais. Com isso, a ênfase estava posta na passagem progressiva "do bom senso à experiência, da reflexão inteligente à experimentação metódica" (JUIF; DOVERO, 1972, p. 22).

A escola da experiência passa, assim, a dar lugar ao laboratório pedagógico, ou seja, o que antes eram vivências agora são ensaios. Laboratórios são abertos nas escolas da França e Alemanha a partir de 1889 e, desde então, dão andamento a experimentações psicológicas. De Herbart, assimilaram o modelo de classes de aplicação que passou a ser compreendido como amostra real e finalidade dos testes. Nas palavras de Raymond Buyse em conferência no II Congresso Internacional do Ensino Universitário, ocorrido em Florença no ano de 1957 -, a pedagogia experimental,

relativamente autônoma em seu processo de investigação, é indutiva, objetiva, precisa, quantitativa e controlável. Esforça-se no sentido de resolver as questões controvertidas, ou os problemas suscitados pela ação pedagógica, não com argumentos, mas com verificações, com provas. Para ser eficaz, a experimentação pedagógica deve estudar verdadeiras questões escolares em amostras estratificadas de alunos a trabalhar normalmente nas condições ordinárias das escolas públicas e isso para aperfeiçoar os processos de ensino e de educação. Essas condições são absolutamente indispensáveis, se se quiser poder proceder à aplicação generalizada dos resultados de suas pesquisas. (MIALARET; DOTTRENS, 1974, p. 37)

O modelo de ciência pedagógica argumentado por Buyse é,de forma clara, tomado de empréstimo das ciências da natureza. Indução, objetividade e controle de variáveis são típicas atribuições à física ou a química, por exemplo. A quantificação e a autonomia são garantidas no modelo exposto pelo uso da linguagem universal das ciências naturais - a matemática.

Para a consolidação dessa ciência pedagógica em questão é necessário, antes de tudo, desclassificar o que era feito antes em matéria de pedagogia, por isso, defende Buyse, se antes os problemas educativos eram mediados pelo argumento, agora, serão comprovados pela verificação. Reforça ainda esse posicionamento, quando afirma que os verdadeiros problemas da educação devem ser colocados em uma análise experimental, possivelmente, em oposição às questões filosóficas que, de fato, não se enquadrariam em categorias e medidas educacionais.

Fruto disso é que a pedagogia experimental se impôs, senão com autonomia, certamente, com autoridade. A elaboração de escalas para medição de inteligência, classificação do desenvolvimento biológico e de uma 
gama de instrumentos de mensuração, aplicação e avaliação da educação, bem como, a edição de uma série de manuais de pedagogia experimental, psicologia da aprendizagem e psicopedagogia convenceram, de certo modo, professores, especialistas e sociedade da necessidade de cientificizar não só a discussão, mas a prática pedagógica.

Em Pedagogia científica ${ }^{16}$ de A. M. Aguayo, de 1936, a sustentação da pedagogia como ciência se faz sobre a psicologia e psicologia da aprendizagem. Trata-se de uma abordagem essencialmente experimental e obra continuada do seu Tratado de psicologia pedagógica, publicado em 1925. Aguayo se dedicou, além da publicação de obras de psicologia escolar, ao tratamento da didática na escola primária e à higiene escolar, todas, com a preocupação de difundir o estudo e aplicação da pedagogia ativa.

Na obra em questão, o autor inicia o debate argumentando que a diferença nítida da educação tradicional, e ainda predominante, para a educação nova, ativa ou progressista, está no entendimento acerca do conceito de aprendizagem; e exemplifica afirmando que, na escola comum, o professor ensina, enquanto na escola ativa, baseadas nos estudos e nas teorias psicológicas, "as crianças aprendem por si mesmas, e o mestre se limita a dirigi-las, estimulá-las e animá-las" (AGUAYO, 1936, p. 10). Nesse sentido, a psicologia é não apenas a base de sua obra, mas a base em que se funda a pedagogia como ciência.

Aguayo, por um lado, critica Herbart - entre outros pensadores anteriores e classificados como experiencialistas - por acreditar que as técnicas e métodos propostos por eles não têm a universalidade que proclamavam e que, em síntese, não passavam de generalizações, de princípios ou doutrinas. Por outro lado, reconhece o esforço de Herbart em sua formulação didática, de modo especial, o método desenvolvido por ele, chamado de passos formais da instrução, ${ }^{17}$ mas aplica-lhe ressalvas na sua execução, como por exemplo, a ineficiência em algumas disciplinas e a autonomia com que o aluno se comporta diante do método. De forma geral, fica anunciada a intenção em qualificar a psicologia, em detrimento da filosofia, eixo principal da pedagogia da experiência.

A preocupação de Aguayo era a constituição de uma base material, composta por uma série de obras, para a promoção, em escolas e centros de formação de professores, do que ele chamou de pedagogia prática, em face às elaborações muito abstratas e reflexivas que, pouco ou quase nada, chegavam ao professor e aos alunos, comuns nos tratados de pedagogia até então disponíveis.

O caráter científico de sua obra fica por conta da fundamentação empirista (observação e experimentação psicológicas) como, a título de 
exemplo, no seu prefácio anuncia: "procurei ater-me às da investigação científica, dando muito pouca importância a opiniões pessoais de psicólogos e pedagogistas [...] por isso que dei o título de Pedagogia científica" (AGUAYO, 1936, p. 10). Além disso, dedica um capítulo para os métodos de investigação da psicologia da aprendizagem e outro voltado para a utilização do método estatístico nas pesquisas educacionais.

Aguayo, como fizeram Debesse e Mialaret na filosofia, realiza o exercício de sobrelevar sua ciência ao custo de minimizar a atuação das demais no campo educativo. Chama de ciências auxiliares da psicologia da aprendizagem: a Biologia, fundamental para o desenvolvimento da psicologia geral e genética e, assim, compreender e lidar com o indivíduo; e, também, a Sociologia, que aplicada à psicologia social é capaz de subsidiar o estudo sobre educação simultânea, sociabilidade e relação professor-aluno. Sendo, nas palavras do autor, a psicologia da aprendizagem uma ciência aplicada, cabe a ela também fundamentar-se nos princípios da psicologia geral.

Recorrente, tal posicionamento de fazer ofuscar qualquer concorrência em matéria de definir uma pedagogia científica e, principalmente, de defender os modelos que seriam sua fundamentação, também fez René Hubert na sua História da pedagogia, ${ }^{18}$ publicada originalmente, em 1949, na França e, em 1976, no Brasil. Começa sua obra criticando o trabalho empreendido por Compayré de construir um histórico geral da educação, sobretudo na França, classificando seus estudos em obsoletos e limitados para as necessidades da época (HUBERT, 1976).

No entanto, ressalta que o ponto de vista sociológico, quando aplicado por Compayré à explicação dos fatos e doutrinas, é bem visto. Começa assim, a anunciar a sociologia como base da pedagogia científica que propõe defender. E, da mesma forma que Aguayo, Hubert pretende fazer uma obra de finalidade prática, "primeiro para os educadores, depois para os filósofos" (HUBERT, 1976, p. s/n).

René Hubert era professor da Universidade de Estrasburgo e foi reitor da mesma instituição quando da publicação desse livro. A característica dessa universidade e da região onde se situa traz, na sua história, aproximações e embates com a vizinha Alemanha com que, nas duas Grandes Guerras, esteve em contenda, vivenciando, não só no campo militar, o trânsito entre alemães e franceses. Com isso, percebe-se, fortemente, a presença da sociologia francesa na sua História da Pedagogia, mas, também são perceptíveis traços que remetem ao historicismo alemão.

Hubert está preocupado em compreender a educação e a pedagogia por meio da abordagem sociológica e, com isso, concentra sua análise na 
definição da instituição escolar como fenômeno social, na caracterização do fato pedagógico ${ }^{19}$ e como as doutrinas se relacionam a eles. Dessa forma,

Experimentaríamos ainda mais completamente tais benefícios do conhecimento do passado, se fosse possível passar do ponto de vista histórico para o da sociologia educacional comparada [...] Permitiria ela, no mínimo, estabelecer a relação que une as doutrinas da educação aos fatos pedagógicos. (HUBERT, 1976, p. 4-5)

Assim, em uma perspectiva positivista, Hubert estabelece o papel da disciplina História, que Comte já havia definido, como responsável por recolher, coligir e organizar documentos que, posteriormente, seriam analisados pelo sociólogo, cientista capaz de utilizar esse material para além da observação e da descrição, pois, sendo

[...] possível provar experimentalmente que há uma curva da evolução pedagógica através dos séculos ou, ao menos, descobrir sinais marcantes de sua existência, a sociologia educacional comparada teria fornecido séria contribuição. (HUBERT, 1976, p. 5)

Dessa forma, até o momento, o panorama constituído é formado por um conjunto de tentativas em atribuir à pedagogia uma cientificidade sustentada ora pela filosofia, ora pela psicologia ou sociologia - que, muitas vezes, revela-se limitada, condicionadora e um tanto romântica. Assim, a pedagogia tem sido admitida de duas formas gerais, como: (1) ciência prática, ${ }^{20}$ como definem Aguayo (1936) e Hubert (1976), exigente de uma teorização (que não lhe é própria) a ser concedida pelo aporte da psicologia da aprendizagem e da sociologia educacional comparada; e (2) ciência interdisciplinar, como argumentam Debesse e Mialaret (1974), compreendida no plural e, por isso, ciências pedagógicas. Um conjunto de disciplinas, que ocupadas da formação do homem, convergem em torno da filosofia, para a constituição das ciências da educação. Essa forma, no decorrer da História da educação, tem sido a saída mais usual para o problema epistemológico que,

Perante as ambiguidades do termo Pedagogia, [...] certos pensadores de ontem e de hoje mostraram a sua preferência por uma noção que é simultaneamente mais extensa e menos ambiciosa: a de Ciências da Educação (JUIF; DOVERO, 1972, p. 22).

Mesmo confortante, tal explicação evidenciou uma situação contraditória vivida pela pedagogia no que diz respeito à necessidade de se estabelecer uma epistemologia própria. Segundo Adalberto Dias de Carvalho em 
Epistemologia das ciências da educação, a pedagogia como ciência tradicional da educação transita, assim,

em primeira análise, de uma via unidisciplinar a uma outra multi ou pluridisciplinar que se exprime através de uma mutação terminológica, a qual passa, numa fase intermediária, pelas "ciências pedagógicas". A passagem do singular ao plural é acompanhada, finalmente, por um lado, pelo abono do vocabulário ("pedagogia"), e por outro, pela introdução do termo "educação". (DIAS DE CARVALHO, 1988, p. 186)

Percebe-se, portanto, que o empreendimento da pedagogia científica contou, ao longo desses dois últimos séculos, com diferentes atores e ações não menos diversas, atuando em sua defesa. Os vários países europeus, por exemplo, tiveram que se "pedagogizar"21 na medida que almejavam adentrar o mundo moderno (p. 418).

Outra via estruturante desse movimento esteve centrada na criação da disciplina História da pedagogia 22 em diversos países europeus, com a finalidade de oferecer um conjunto de conhecimentos organizados segundo o método da história, a fim de subsidiar a formação do futuro professor primário por meio da História da educação e, sobretudo, a história do sistema de ensino (público, estatal e obrigatório) ao qual seria o novo mestre incorporado.

A História da pedagogia, disciplina vinculada, sobretudo, à formação de professores primários, nasce no final do século XVIII. Desenvolve-se durante o século seguinte e tem no ensino a base de sua constituição. Exemplo disso é o fato de que as lições de pedagogia ou de História da pedagogia tomaram a forma de manuais e foram difundidos por todo mundo, onde fosse oferecida essa disciplina. Característica geral, a pesquisa nessa área era feita

por pessoas ligadas à escola, empenhadas na organização de uma instituição cada vez mais central na sociedade moderna (para formar técnicos e para formar cidadãos), preocupadas, portanto, em sublinhar os aspectos mais atuais da educação-instrução e as ideias mestras que haviam guiado seu desenvolvimento histórico. (CAMBI, 1999, p. 21)

Era, assim, um composto de estudo da legislação - uma vez que, o conhecimento das leis educacionais atuais comunica o contexto que deve ser assimilado - e do estudo das ideias e feitos dos grandes pedagogos, sequenciados cronologicamente, baseados no sentido de progresso. $\mathrm{O}$ conhecimento do passado transitava entre a lição do que não fazer ou do não foi feito e a justificativa e glória do presente. Em meio a uma seleção de fatos, concepções e personalidades, 
A História da Pedagogia nascia como uma história ideologicamente orienta$\mathrm{da}$, que valorizava a continuidade dos princípios e dos ideais, convergia sobre a contemporaneidade e constituía o próprio passado de modo orgânico e linear, pondo particular acento sobre os ideais e a teoria, representada, sobretudo, pela Filosofia. (CAMBI, 1999, p. 21-22)

Consequentemente, esse foi o modelo empregado à produção literária em História da educação/da pedagogia. A publicação de lições, manuais e tratados que se ocupavam da temática registrou crescimento sem precedentes no período que vai da segunda metade do século XIX até a Primeira Guerra Mundial. Mais precisamente, a História da educação, "no período de 1880-1900, conhece sua 'idade do ouro', com imensa produção de monografias, amplas sínteses, obras coletivas, dirigidas por nomes como Gréard, Liard, Buisson, Compayré" (BASTOS, 2009, p. 158).

Portanto, o papel desempenhado pela disciplina histórica aplicada à pedagogia foi fundamental para o seu autorreconhecimento. Conforme Nóvoa (1996), a descoberta de uma história prévia fez estruturar a pedagogia como ciência da educação. Nas palavras de Nanine Charbonnel (1988) "Pedagogia e História da pedagogia sustentam-se mutuamente [e] somos levados a crer que a primeira existe porque a segunda partiu à procura de suas origens". Para Compayré (1911), "a história é a introdução necessária, a preparação para a própria ciência" da educação (NÓVOA, 1996, p. 417-418).

Nesse empreendimento, destaca Julia (1993), o modelo francês - permeado pela presença ideológica propagada pela Revolução Francesa a qual, segundo o autor, "se pensou e quis ser inteiramente projeto pedagógico" (p. 264) - foi responsável por produzir uma tradição de escola e de historiografia que remete à ideia do mito fundador. Nesse sentido, Julia argumenta que foi característica na História da educação, entre os anos de 1871 e 1914, dois tipos de produção histórica:

de uma parte, uma história institucional que se apoia mais em textos regulamentares ou normativos do que no funcionamento social das escolas, e que rejeita para o lado da sombra a educação extraescolar; de outra parte, uma análise dos projetos e das utopias dos grandes pedagogos que se prende - como explica Gabriel Compayré, em sua Histoire critique des doctrines de l'éducation en Frence depuis le seizième siècle - à "história geral das crenças e também à explicação filosófica das ações humanas". A história torna-se então o ponto em que "se procuram verdades duradouras e se busca recolher os elementos de uma teoria definitiva" para o futuro. (JULIA, 1993, p. 265 destaques originais) 
Em síntese, a constituição disciplinar da História da pedagogia/ da educação se deu, segundo Nóvoa (1996), mediante três processos simultâneos: (1) a cientificização da pedagogia e a disseminação desse saber; (2) a ação estatal sobre o ensino, tornando-o público, gratuito e obrigatório; e, (3) a institucionalização da formação para o magistério, por meio da regulamentação do acesso à carreira docente e a oficialização de modelos formativos.

\section{CONSIDERAÇÕES}

A questão da autonomia ou mesmo da cientificidade da pedagogia mostra-se problemática até mesmo na contemporaneidade. Nesse sentido, a História da pedagogia pouco agiu, mesmo porque, logo no início do século XX, a disciplina perde sua função teorizante para se submeter a uma função repositória, nos moldes, segundo Nóvoa (1996), de uma "ciência de observação, numa disciplina sem qualquer utilidade" (Nóvoa, 1996, p. 419).

Assim, ao mesmo tempo que a pedagogia busca se institucionalizar, as críticas e ataques a essa "pseudociência, estéril e inútil" se intensificam (p. 418). $O$ autor divulga alguns dos comentário ${ }^{23}$ combativos que especialistas de outras áreas direcionavam a quem se ocupava do estudo desse conhecimento. Alegava-se ser desnecessário e equivocado qualquer tempo dedicado à pedagogia. Contudo, sem a pretensão de resolver a contenda ou mesmo esgotar o debate, chega-se ao entendimento de que custou muito caro à pedagogia pretender o seu estatuto científico.

Todo esforço dedicado a dotação de cientificidade à pedagogia pode ter levado ao seu próprio esvaziamento. Como argumenta Franco (2008), "o princípio de cientificidade, estruturado pós-Herbart, foi gradativamente impondo um fechamento de horizontes à pedagogia de tal forma que, para ser ciência, teve que deixar de ser pedagogia" (FRANCO, 2008, p. 61). $O$ investimento em definir seu objeto, por exemplo, acabou por reduzila, drasticamente, ao ensino e à ação escolar. A adoção de modelos de cientificidade nas ciências humanas em geral (JAPIASSU, 1978, p. 96), muitas vezes específicos das ciências naturais, impôs à pedagogia o objetivo único em suas investigações, a construção de modelos explicativos e globalizantes, algo muito difícil, tendo visto que são raras as generalizações possíveis, pois, o que guia uma preocupação educacional, por exemplo, é a necessidade interpretativa e compreensiva de fatos ou problemas. 
THE PLACE OF PEDAGOGY IN THE SCIENTIFIC WORLD AND THE ROLE OF FUNDAMENTAL SUBJECTS

AвSTRACT: This article deals with the historical approach to the constitution or constitutive intention of pedagogy as the science of education. By means of a specialized bibliography, especially that of the History of Education/Pedagogy, it sets out to analyze the affirmative action of the classical science model which was imposed on Pedagogy in the twentieth century. The method used for this research centered on a comparative analysis of the works and identification of the origins of pedagogical thinking. It can be seen that Pedagogy produced different results from those expected, often resulting in the exhaustion of pedagogical reflection itself.

Keywords: History of education. Pedagogy. Experience. Experiment.

\section{EL LUGAR DE LA PEDAGOGÍA EN EL MUNDO CIENTÍFICO Y EL PAPEL DE LAS DISCIPLINAS DE BASE}

ReSUMEN: El artículo a continuación trata del abordaje histórico de la constitución o pretensión constitutiva de la pedagogía como ciencia de la educación. Tiene como objetivo, analizar, por medio de la bibliografía especializada, sobretodo de la Historia de la Educación/Pedagogía, las acciones afirmativas del modelo clásico de ciencia que se impuso a la Pedagogía ya en el siglo XX. El método utilizado para esa investigación estuvo centrado en el análisis comparativo de las obras y en la identificación de las matrices del pensamiento pedagógico. Se percibe que, con tal emprendimiento, la pedagogía obtuvo resultados diferentes de lo esperado, resultando, muchas veces, en el agotamiento de la propia reflexión pedagógica.

Palabras-claves: Historia de la educación. Pedagogía. Experiencia. Experimento.

\section{NOTAS}

1. Essa resistência se dava, sobretudo, à falta de rigor científico possível de se alcançar somente por meio dos modelos de cientificidade estabelecidos - das ciências naturais (Ver JAPIASSU, 1978).

2. Segundo Japiassu (1978), "as ciências humanas nasceram da deposição do sujeito pensante no século XIX" (p. 91) e, por isso, não são nem anexo da filosofia nem seu aperfeiçoamento.

3. Os eixos epistemológicos constituem as bases das ciências humanas, principalmente fornecendo modelos científicos e de reconhecimento, como a garantia de objetividade. São eixos: ciência rigorosa ou da natureza, biologia, cultura e história (JAPIASSU, 1978).

4. Foi responsável pela organização e difusão, no século XVIII, do método silábico de aprendizagem, da leitura codificada, influenciado pelo racionalismo cartesiano. 
5. Segundo Gauthier (2010), "Atribui-se a Charles Démia uma das primeiras tentativas de formação de mestres (MARC, apud AVANZINI, 1981, p. 250). Démia, que se inspira abundantemente na obra de De Batencour (1669), cria o primeiro organismo francês de formação de mestres em 1978. Os Irmãos das Escolas Cristãs, comunidade exclusivamente consagrada ao ensino [...]" (GAUTHIER; TARDIF, 2010, p. 134).

6. A partir de La conduite dês écoles chrétiennes, p. 305-312, basicamente, um exercício de formação moral (Cf. Mialaret; Dottrens, op. cit., 1974).

7. A cidade de Estrasburgo pertenceu à Alemanha entre 1871-1919; após esse período passou a pertencer ao Estado francês, por meio do Tratado de Versalhes.

8. Deveria ser conforme definido pelo Decreto n. 980, de 8 de novembro de 1890, como "um centro impulsor de reformas e melhoramentos de que carece a instrução nacional, oferecendo aos professores públicos e particulares os meios de instrução profissional de que possam carecer [...]"(ARAÚJO; GATTI JR, 2006, p. 115).

9. No Brasil, a circulação dessas obras é abordada por trabalhos dedicados aos manuais escolares, principalmente de História da Educação. No primeiro momento, há registros da circulação de textos na língua original, principalmente, francês, alemão e inglês. Posteriormente, por meio da ação do mercado editorial que se estrutura em torno da educação no país, passa-se a contar com traduções e edições comentadas. Ver Bastos (2009, 2007 e 2006); Gatti Jr. (2007 e 2009); Monarcha (2009); Nunes (1996) e Saviani (2008).

10. Essa obra compõe uma coletânea de cinco volumes: I- Tratado das ciências pedagógicas; II - História da Pedagogia; III - Pedagogia comparada; IV - Psicologia da educação; e, V - Psicologia pedagógica.

11. Quanto à escolha das obras é necessário fazer um agradecimento especial ao Prof. Dr. José Carlos Souza Araujo, quem indicou a maioria delas com especial atenção ao objeto de pesquisa.

12. O crescimento da Companhia Editora Nacional é creditado ao desenvolvimento do ensino secundário, à expansão do ginásio pelo interior e à organização da formação de professores em escolas normais, institutos de educação e faculdades de filosofia no país, sobretudo, a partir dos anos 1940 e 1950. Em 1980 o IBEP - Instituto Brasileiro de Edições Pedagógicas - adquire a empresa. A publicação da coleção Atualidades pedagógicas é encerrada em 1978 (Ver HALLEWELL, 2005).

13. Publicado pela Cia. Editora Nacional como parte integrante da coleção Atualidades pedagógicas. Do original em francês: Traité dês sciences pédagogiques, Presses Universitaires de France, 1969.

14. O termo pedagógicas foi cunhado a partir da definição dos autores que classificam essas disciplinas como aquelas dedicadas ao "estudo dos métodos de educação". (MIALARET; DOTTRENS, p. 32-41 apud DEBESSE; MIALARET, 1974). 
15. Dentre as chamadas ciências da educação, a Filosofia da educação é a única a ter amplo espaço dedicado no Tratado, sendo que, em outros dois tomos, disciplinas como História da pedagogia, Educação comparada e Psicopedagogia ganham tratamento específico. São seis tomos no total.

16. Volume 15 da série Atualidades Pedagógicas, Companhia Editora Nacional.

17. São cinco passos no total: preparação; apresentação; associação; recapitulação e a aplicação; e, dizem respeito ao processo que orienta o aprendizado, a partir de uma ideia de começo-meio-fim do assunto abordado (Ver AGUAYO, 1936, p. 247-249).

18. Volume 66 da série Atualidades Pedagógicas, Companhia Editora Nacional.

19. Hubert inspira-se em Durkheim para definir o fato pedagógico em alusão ao fato social. O fato social pode ser compreendido como um uma forma de indução sobre os sujeitos e independente de vontade individual. Também se define o fato social como uma norma coletiva com independência e poder de coerção sobre o indivíduo.

20. Ou ainda, tomar a pedagogia como uma teoria prática, na acepção de Émile Durkheim.

21. Expressão de Félix Pécault (1882) apud NÓVOA, 1996, p. 418.

22. Até 1905, a nomenclatura história da pedagogia era unânime, sobretudo, na França (COMPAYRÉ, 1911, apud BUISSON, Ferdinand. Dictionnaire de pédagogique et d'istruction primaire. Ed. online: INRP.

23. Alguns comentários - de Ferdinand Brunetière: "[...] queremos acima de tudo professores que se dediquem a professar, e que não liguem nehuma à pedagogia"; de Daniel Hameline:"torna-se moda troçar dos pedagogos. É um dever. Uma cruzada, quase"; e deThéodore Barrau: "ciência laboriosamente inútil" (Ver NÓVOA, 1996, p. 418-419)

\section{REFERÊNCIAS}

AGUAYO, A. M. Pedagogia científica. São Paulo: Companhia Editora Nacional, 1936.

ANíSIO, P. Tratado de pedagogia. Rio de Janeiro: Civilização Brasileira, 1934.

ARAÚJO, J. C. S.; GATTI JR., D. O ensino baseado em pesquisas e estudos como diretriz de Centro Educacional de Pesquisas Educacionais de Minas Gerais. In: ARAÚJO, M. M.; BRZEZINSKI, i. (Org.). Anísio Teixeira na direção do INEP: programa para a reconstrução da nação brasileira (1952-1964). 1. ed. v. 1. Brasília: Instituto Nacional de Pesquisas Educacionais Anísio Teixeira, 2006. p. 113-141.

BASTOS, M. H. C. Uma biografia dos manuais de História da Educação adotados no Brasil (1860-1950). Anais do VI Congreso Luso Brasileiro de História da Educação. Uberlândia-MG, 17 a 20 abr. 2006. p. 334-349. 
BASTOS, M. H. C. Pedagogia e manuais - leituras cruzadas. Os manuais de História da Educação adotados no Brasil (1870-1950). Porto Alegre: Pontifícia Universidade Católica do Rio Grande do Sul, 2007.

BASTOS, M. H. C. Paroz, Compayré, Rousselot: manuais de História da Educação em circulação no Brasil (século XIX). In: GATTI JR., D.; MONARCHA, C.; BASTOS, M. H. C. (Org.). O ensino de História da Educação em perspectiva internacional. 1. ed. v. 1. Uberlândia: EdUFU, 2009. p. 95-130.

BLOCH, M. Apologia da História: ou ofício de historiador. Rio de Janeiro: Jorge Zahar Editor, 2001.

CAMBI, F. História da pedagogia. Trad. Á. LORENCINI. São Paulo: FEU/UNESP, 1999.

DEBESSE, M.; MIALARET, G. Tratado das ciências pedagógicas, v. 1. São Paulo: Companhia Editora Nacional, 1974.

DIAS DE CARVALHO, A. Epistemologia das ciências da educação. Porto: Edições Afrontamento, 1988.

FRANCO, M. A. Pedagogia como ciência da educação. São Paulo: Cortez, 2008.

GATTI JR., D. Percurso histórico e desafios da disciplina História da Educação no Brasil. In: GATTI JR., D.; PINTASSILGO, J. Percursos e desafios da pesquisa e do ensino de História da Educação. Uberlândia: EdUFU, 2007. p. 99-142.

GATTI JR., D. Investigar o ensino de História da educação no Brasil: categorias de análise, bibliografia, manuais didáticos e programas de ensino. In: GATTI JR, D.; MONARCHA, C.; BASTOS, M. H. O ensino de História da educação em perspectiva internacional Uberlândia: EdUFU, 2009. p. 95-130.

GATTI JR., D. Intelectuais e circulação internacional de ideias na construção da disciplina História da Educação no Brasil (1955-2008). In: CARVALHO, M. M.; GATTI JR., D. O ensino de História da Educação. Vitória, ES: EDUFS, 2011. p. 47-93.

GAUTHIER, C.; TARDIF, M. Pedagogia: teorias e práticas da Antiguidade aos nossos dias. Petrópolis: Vozes, 2010.

HALLEWELL, L. O livro no Brasil: sua história. São Paulo: EdUSP, 2005.

HUBERT, R. História da pedagogia. São Paulo: Companhia Editora Nacional, 1976.

JAPIASSU, H. Nascimento e morte das ciências humanas. Rio de Janeiro: Francisco Alves, 1978.

JUIF, P.; DOVERO, F. Guia do estudante de ciências pedagógicas. Lisboa: Editorial Estampa, 1972.

JULIA, D. Educação [verbete]. In. BURGUIÈRE, A. Dicionário das ciências históricas. Rio de Janeiro: Imago, 1993. p. 264-275.

LÉVÊQUE, R.; BEST, F. Por uma filosofia da educação. In: MIALARET, G. Tratado das ciências pedagógicas. São Paulo: Ed. Nacional, 1974. 
LUZURIAGA Y MEDINA, L. História da educação e da pedagogia. São Paulo: Companhia Editora Nacional, 1969.

MIALARET, G.; DOTTRENS, R. O desenvolvimento das ciências pedagógicas e seu estado atual. In: DEBESSE, M.; MIALARET, G. Tratado das ciências pedagógicas, v. 1. São Paulo: Companhia Editora Nacional, 1974. p. 11-78.

MONARCHA, Práticas de escrita da História da Educação: o tema da Escola Nova nos manuais de autores brasileiros. In: GATTI JR., D.; MONARCHA, C.; BASTOS, M. H. C. O ensino de História da Educação em perspectiva internacional. 1. ed. v. 1. Uberlândia: EdUFU, 2009. p. 65-94.

NÓVOA, A. História da educação: percursos de uma disciplina. Análise Psicológica , p. 417-434, 1996.

NUNES, C. Ensino e historiografia da educação: problematização de uma hipótese. Revista Brasileira de Educação, p. 417-434, 1996.

PATRÍCIO, M. F. Antelóquio. In HERBART, J. F. Pedagogia Geral. Trad. Joaquim Ferreira Gomes. Lisboa: Fundação Caloustre Gulberkian, 1971. p. v-xi.

SAVIANI, D. História da História da Educação no Brasil: um balanço prévio e necessário. Eccos Revista Científica, v. 10, p. 147-167, 2008

TOLEDO, M. R. Circulação de modelos de leituras para professores: a atualidade pedagógica e a biblioteca museu do ensino primário. 30ª Reunião Anual da Anped . Rio de Janeiro: Anped, 2007. p. 1-15.

BRUNO GONÇALVES BORGES: mestre em Educação pela UFU; professor no Departamento de Educação da UFG, Câmpus Catalão; integrante do Grupo de Estudos e Pesquisas sobre a Disciplina História da Educação - GEPEDHE; vinculado ao Núcleo de Estudos e Pesquisas em História e Historiografia da Educação - NEPHE/UFU.

E-mail: brunogoncalvesborges@hotmail.com

DÉCIO GATTI JúNIOR: mestre e doutor em Educação História e Filosofia da Educação pela PUC-SP, com estágio pós-doutoral realizado na Faculdade de Educação da USP; professor da Faculdade de Educação e do Programa de Pós-Graduação em Educação da UFU; coordenador do Núcleo de Estudos e Pesquisas em História e Historiografia da Educação; líder, em parceria, do Grupo de Estudos e Pesquisas sobre a Disciplina História da Educação - GEPEDHE.

E-mail: degatti@ufu.br 